\title{
Exploring the Links Between Social Exclusion and Substance Use, Misuse, and Addiction
}

\author{
Eric D. Wesselmann ${ }^{1 *}$ and Leandra Parris ${ }^{2}$ \\ ${ }^{1}$ Department of Psychology, Illinois State University, Normal, IL, United States, ${ }^{2}$ School of Education, College of William \& \\ Mary, Williamsburg, VA, United States
}

Keywords: social exclusion, trauma-informed approaches, ostracism, interpersonal rejection, substance use

\section{INTRODUCTION}

Humans have a central need to belong, their daily efforts predominately focused on forging-and maintaining-stable social connections (Baumeister and Leary, 1995; Lieberman, 2013; Gabriel, 2021). The downside of being inherently social is that interpersonal interactions are not always positive. Situations in which someone feels physically or emotionally separate from others, termed social exclusion (Riva and Eck, 2016), are common and aversive. Exclusion often evokes immediate pain sensations (Eisenberger, 2012), unpleasant emotions (e.g., anger, sadness,

OPEN ACCESS

Edited by:

Andrea D. Clements, East Tennessee State University,

United States

Reviewed by:

Karen Hanson,

Yale University, United States

Elena Argento,

University of British

Columbia, Canada

${ }^{*}$ Correspondence: Eric D. Wesselmann edwesse@ilstu.edu

Specialty section: This article was submitted to

Health Psychology, a section of the journal

Frontiers in Psychology

Received: 01 March 2021 Accepted: 21 May 2021

Published: 18 June 2021

Citation:

Wesselmann ED and Parris L (2021) Exploring the Links Between Social

Exclusion and Substance Use, Misuse, and Addiction.

Front. Psychol. 12:674743.

doi: $10.3389 /$ fpsyg.2021.674743 shame) and threatens core psychological needs beyond belonging, such as needs for positive self-esteem, control, and perceived meaningful existence (Williams, 2009). Excluded individuals often experience loneliness and develop social anxiety, fearing, and expecting future exclusion (Cacioppo and Patrick, 2008). Chronically excluded individuals also report experiencing higher levels of depressive symptoms, helplessness, alienation, and perceived existential meaninglessness (Riva et al., 2017). Individuals from stigmatized groups (e.g., immigrants, formerly incarcerated persons) are most likely to experience chronic exclusion (Kurzban and Leary, 2001). In some cases, such as mental illness stigma, specific instances of exclusion may exacerbate symptoms, thus leading to a cycle of further exclusion (Reinhard et al., 2020).

\section{SOCIAL EXCLUSION, TRAUMA, AND SUBSTANCE (MIS)USE}

We have argued elsewhere (Wesselmann and Parris, 2020) that these various adverse outcomes suggest chronic social exclusion should be treated as a form of trauma: a psychological experience involving intense physical or emotional harm that inflicts lasting damage on one's physical or mental health (Substance Abuse Mental Health Services Administration [SAMHSA], 2014, p. 7). Exclusion-based trauma may also dovetail with trauma from other experiences (e.g., military combat experience; Wesselmann et al., 2018), compounding the individual's suffering. As such, it is important for trauma-focused researchers and therapists to investigate the specific trauma sources to better understand the psychological processes and possible solutions.

Several studies have established a connection between trauma (broadly defined) and substance (e.g., alcohol, narcotics) use and misuse, the latter generally involving excessive, often repeated, use in ways that do not align with medical or general usage, causing physical or psychosocial harm to self or others (Substance Abuse Mental Health Services Administration, 2014; Roberts et al., 2015). Related to social exclusion, other studies have established correlations between both loneliness (Cacioppo and Patrick, 2008; DeWall and Pond, 2011; Dyal and Valente, 2015) and stigma-based exclusion with reported substance use/misuse (e.g., Scheim et al., 2017). Still, these links are only indirect. Establishing such links causally is difficult, if not impossible, given the ethical and practical issues with studying misuse behaviorally. To our knowledge, there is only one experiment that 
directly examines substance use as a dependent outcome after experiencing social exclusion (Bacon and Engerman, 2018). This study found a marginally significant increase in the amount of alcohol consumed by excluded (vs. included) participants in an online interaction.

However, other studies have examined how the use of analgesic substances affects the immediate psychological impact of exclusion. These studies have built on the general assumption that physical and social pain share similar neurological underpinnings (Eisenberger, 2012). First, researchers demonstrated that participants who ingested acetaminophen (compared to a placebo group) showed reduced reactivity to a social exclusion manipulation (DeWall et al., 2010). Subsequent researchers found that other analgesic substances, such as alcohol (Hales et al., 2015), marijuana (Deckman et al., 2014), and psilocybin (a key chemical in hallucinogenic mushrooms; Preller et al., 2016) also dull the immediate sting of social exclusion. Further, one study found that substance use (i.e., alcohol consumption) is most effective for dulling the pain of exclusion in casual users, whereas heavy users may not receive numbing benefits (Buckingham et al., 2016). Relatedly, neurological research has found heightened activity in brain regions associated with exclusion-related pain and reduced ability in regulating this pain for alcohol-dependent participants (Maurage et al., 2012). Other studies demonstrate differential reactions to exclusion among users of opioids, finding that these individuals can have higher adverse reactions to exclusion than non-users (e.g., Kroll et al., 2019; Carlyle et al., 2020).

Collectively, these studies suggest that individuals who use substances to numb the immediate pain of social exclusion may ultimately face diminishing returns; as they build a tolerance for the substance, they may also experience reduced analgesic effects for dealing with social exclusion, perhaps even heightened sensitivity. Thus, although substance use (no matter how moderate) may be a functional way of dealing with exclusionrelated pain in the short-term, it could become habit-forming and lead to addiction.

\section{DISCUSSION}

When someone seeks treatment for substance misuse or addiction, a therapist taking a trauma-informed approach should identify to what degree social exclusion contributes to their presenting concerns. Social exclusion may be the primary cause (i.e., chronic social exclusion was the main trauma elicitor), or it may be a secondary cause; perhaps their initial trauma elicitor was something other than exclusion, and their subsequent substance misuse has led their previous social support network to exclude them. Trauma-informed treatment approaches often focus on social support as a key factor in trauma recovery (Substance Abuse Mental Health Services Administration, 2014). The therapeutic alliance offers an important source of social support for clients throughout treatment, likely increasing their sense of belonging (Baumeister and Leary, 1995). Further, therapists should consider integrating multiple forms of social support when determining treatment modality and access (e.g., group counseling, visitation during hospitalization) to maintain clients' sense of belonging as much as possible (Riva, 2016).
Unfortunately, not all social support is beneficial. People who misuse substances may surround themselves with others who misuse both to receive validation and satisfy their need for belonging (DeWall and Pond, 2011; Mead et al., 2011, Experiment 4). Thus, therapists may want to address the dual nature these enablers can have on clients, because both aspects likely contribute to any resistance to adjusting clients' social networks.

Additionally, therapists could encourage clients to pursue alternative ways of coping with exclusion (Riva, 2016). For example, people can recover from exclusion by engaging in self-affirmation tasks (Knowles et al., 2010; Hales et al., 2016). However, the effectiveness of self-affirmation can depend upon the source of the exclusion. One study (Stock et al., 2018) examined race-based exclusion, finding that Black participants who were excluded by White computer-controlled players in an online game showed increased vulnerability to substance use, but this effect was mitigated when they could affirm their racial identity. A general self-affirmation task did not have the same protective effect, unfortunately. Other research has found that religious/spiritual interventions can be useful in helping people recover from substance addiction, at least partially through fostering a general sense of interpersonal connectedness (e.g., Piedmont, 2004). Germane to social exclusion research, one study found that prayer can help excluded individuals recover, but that it has its strongest effect for people who are most committed to their religion (Hales et al., 2016); this approach is less helpful for less-religious people. We caution that these studies have examined the utility of these various interventions in laboratory settings only; thus, more research needs to assess their effectiveness within the therapeutic context.

The degree to which current trauma-informed programs address social exclusion is unclear. Most programs (e.g., Jaycox et al., 2012) provide opportunities for the therapist to address specific trauma-related concerns, but do not explicitly target clients' experiences with social exclusion. Thus, it is incumbent upon the therapist to ensure assessing the specific impact and salience of social exclusion is included in treatment. This can include helping clients repair damage to social relationships resulting from substance misuse, creating new opportunities for substance-free social inclusion outside the therapeutic context, and ensuring alignment with clients' cultural values, identities, and experiences when exploring group counseling as a means of socially inclusive therapy.

\section{AUTHOR CONTRIBUTIONS}

All authors listed have made a substantial, direct and intellectual contribution to the work, and approved it for publication.

\section{FUNDING}

This article was supported by Illinois State University's Office of Research and Graduate Studies, College of Arts and Sciences, Department of Psychology, and The College of William \& Mary's School of Education. 


\section{REFERENCES}

Bacon, A. K., and Engerman, B. (2018). Excluded, then inebriated: a preliminary investigation into the role of ostracism on alcohol consumption. Addict. Behav. Rep. 8, 25-32. doi: 10.1016/j.abrep.2018.05.002

Baumeister, R. F., and Leary, M. R. (1995). The need to belong: desire for interpersonal attachments as a fundamental human motivation. Psychol. Bull. 117, 497-529. doi: 10.1037/0033-2909.117.3.497

Buckingham, J., Moss, A., Gyure, K., Ralph, N., Hindocha, C., Lawn, W., et al. (2016). A moderate dose of alcohol does not influence experience of social ostracism in hazardous drinkers. Front. Psychol. 7:555. doi: $10.3389 /$ fpsyg. 2016.00555

Cacioppo, J. T., and Patrick, W. (2008). Loneliness. New York: W. W. Norton and Company.

Carlyle, M., Rowley, M., Stevens, T., Karl, A., and Morgan, C. J. (2020). Impaired empathy and increased anger following social exclusion in non-intoxicated opioid users. Psychopharmacology 237, 419-430. doi: 10.1007/s00213-019-05378-x

Deckman, T., DeWall, C. N., Way, B., Gilman, R., and Richman, S. (2014). Can marijuana reduce social pain? Soc. Psychol. Pers. Sci. 5, 131-139. doi: $10.1177 / 1948550613488949$

DeWall, C. N., MacDonald, G., Webster, G. D., Masten, C. L., Baumeister, R. F., Powell, C., et al. (2010). Acetaminophen reduces social pain: behavioral and neural evidence. Psychol. Sci. 21, 931-937. doi: 10.1177/0956797610374741

DeWall, C. N., and Pond, R. S. (2011). Loneliness and smoking: the costs of the desire to reconnect. Self Identity 10, 375-385. doi: $10.1080 / 15298868.2010 .524404$

Dyal, S. R., and Valente, T. W. (2015). A systematic review of loneliness and smoking: small effects, big implications. Subst. Use Misuse 50, 1697-1716. doi: $10.3109 / 10826084.2015 .1027933$

Eisenberger, N. I. (2012). Broken hearts and broken bones: a neural perspective on the similarities between social and physical pain. Curr. Dir. Psychol. Sci. 21, 42-47. doi: 10.1177/0963721411429455

Gabriel, S. (2021). Reflections on the 25th anniversary of Baumeister and Leary's seminal paper on the need to belong. Self Identity. 20, 1-5. doi: $10.1080 / 15298868.2020 .1850518$

Hales, A. H., Wesselmann, E. D., and Williams, K. D. (2016). Prayer, selfaffirmation, and distraction improve recovery from short-term ostracism. J. Exp. Soc. Psychol. 64, 8-20. doi: 10.1016/j.jesp.2016.01.002

Hales, A. H., Williams, K. D., and Eckhardt, C. I. (2015). A participant walks into a bar...: subjective intoxication buffers ostracism's negative effects. Soc. Psychol. 46, 157-166. doi: 10.1027/1864-9335/a000235

Jaycox, L. H., Kataoka, S. H., Stein, B. D., Langley, A. K., and Wong, M. (2012). Cognitive behavioral intervention for trauma in schools. J. Appl. Sch. Psychol. 28, 239-255. doi: 10.1080/15377903.2012.695766

Knowles, M. L., Lucas, G. M., Molden, D. C., Gardner, W. L., and Dean, K. K. (2010). There's no substitute for belonging: self-affirmation following social and nonsocial threats. Pers. Soc. Psychol. Bull. 36, 173-186. doi: $10.1177 / 0146167209346860$

Kroll, S. L., Williams, D. P., Thoma, M., Staib, M., Binz, T. M., Baumgartner, M. R., et al. (2019). Non-medical prescription opioid users exhibit dysfunctional physiological stress responses to social rejection. Psychoneuroendocrinology 100, 264-275. doi: 10.1016/j.psyneuen.2018.09.023

Kurzban, R., and Leary, M. R. (2001). Evolutionary origins of stigmatization: the functions of social exclusion. Psychol. Bull. 127, 187-208. doi: 10.1037/0033-2909.127.2.187

Lieberman, M. D. (2013). Social: Why Our Brains Are Wired to Connect. New York, NY: Crown Publishers.

Maurage, P., Joassin, F., Philippot, P., Heeren, A., Vermeulen, N., Mahau, P., et al. (2012). Disrupted regulation of social exclusion in alcoholdependence: an fMRI study. Neuropsychopharmacology 37, 2067-2075. doi: 10.1038/npp.2012.54

Mead, N. L., Baumeister, R. F., Stillman, T. F., Rawn, C. D., and Vohs, K. D. (2011). Social exclusion causes people to spend and consume strategically in the service of affiliation. J. Consumer Res. 37, 902-919. doi: 10.1086/656667
Piedmont, R. L. (2004). Spiritual transcendence as a predictor of psychosocial outcome from an outpatient substance abuse program. Psychol. Addict. Behav. 18, 213-222. doi: 10.1037/0893-164X.18.3.213

Preller, K. H., Pokorny, T., Hock, A., Kraehenmann, R., Stämpfli, P., Seifritz, E., et al. (2016). Effects of serotonin $2 \mathrm{~A} / 1 \mathrm{~A}$ receptor stimulation on social exclusion processing. Proc. Natl. Acad. Sci. U.S.A. 113, 5119-5124. doi: 10.1073/pnas.1524187113

Reinhard, M. A., Dewald-Kaufmann, J., Wüstenberg, T., Musil, R., Barton, B. B., Jobst, A., et al. (2020). The vicious circle of social exclusion and psychopathology: a systematic review of experimental ostracism research in psychiatric disorders. Eur. Arch. Psychiatry Clin. Neurosci. 270, 521-532. doi: 10.1007/s00406-019-01 074-1

Riva, P. (2016). "Emotion regulation following social exclusion: Psychological and behavioral strategies," in Social Exclusion: Psychological Approaches to Understanding and Reducing Its Impact, eds P. Riva and J. Eck (Cham: Springer), 199-225.

Riva, P., and Eck, J. (2016). “The many faces of social exclusion," in Social Exclusion: Psychological Approaches to Understanding and Reducing Its Impact, eds P. Riva and J. Eck (Cham: Springer), ix-xv.

Riva, P., Montali, L., Wirth, J. H., Curioni, S., and Williams, K. D. (2017). Chronic social exclusion and evidence for the resignation stage: an empirical investigation. J. Soc. Pers. Relat. 34, 541-564. doi: 10.1177/026540751664 4348

Roberts, N. P., Roberts, P. A., Jones, N., and Bisson, J. I. (2015). Psychological interventions for post-traumatic stress disorder and comorbid substance use disorder: a systematic review and metaanalysis. Clin. Psychol. Rev. 38, 25-38. doi: 10.1016/j.cpr.2015.0 2.007

Scheim, A. I., Bauer, G. R., and Shokoohi, M. (2017). Drug use among transgender people in Ontario, Canada: disparities and associations with social exclusion. Addict. Behav. 72, 151-158. doi: 10.1016/j.addbeh.2017.03.022

Stock, M., Gibbons, F. X., Beekman, J., Williams, K. D., Richman, L., and Gerrard, M. (2018). Racial (vs. self) affirmation as a protective mechanism against the effects of racial exclusion on negative affect and substance use vulnerability among Black young adults. J. Behav. Med. 41, 95-207. doi: 10.1007/s10865-017-9882-7

Substance Abuse and Mental Health Services Administration (2014). TraumaInformed Care in Behavioral Health Services (Treatment Improvement Protocol Series 57; HHS Publication No. [SMA] 14-4816). Rockville, MD. Retrieved from: https://www.integration.samhsa.gov/clinical-practice/ SAMSA_TIP_Trauma.pdf

Wesselmann, E. D., Ispas, D., Olson, M. D., Swerdlik, M. E., and Caudle, N. M. (2018). Does perceived ostracism contribute to mental health concerns among veterans who have been deployed? PLoS ONE 13:e0208438. doi: 10.1371/journal.pone.0208438

Wesselmann, E. D., and Parris, L. (2020). "Inclusion, exclusion, and group psychotherapy: the importance of a trauma-informed approach," in Group Psychology and Group Psychotherapy: An Interdisciplinary Handbook, eds C. D. Parks and G. A. Tasca (Washington, DC: American Psychological Association), 31-50.

Williams, K. D. (2009). "Ostracism: effects of being excluded and ignored," in Advances in Experimental Social Psychology, Vol. 41, ed M. P. Zanna (New York, NY: Academic Press), 275-314.

Conflict of Interest: The authors declare that the research was conducted in the absence of any commercial or financial relationships that could be construed as a potential conflict of interest.

Copyright ( 2021 Wesselmann and Parris. This is an open-access article distributed under the terms of the Creative Commons Attribution License (CC BY). The use, distribution or reproduction in other forums is permitted, provided the original author(s) and the copyright owner(s) are credited and that the original publication in this journal is cited, in accordance with accepted academic practice. No use, distribution or reproduction is permitted which does not comply with these terms. 